\title{
The Wnt modulator ICG-001 mediates the inhibition of nasopharyngeal carcinoma cell migration in vitro via the miR-150/CD44 axis
}

\author{
LAI-SHEUNG CHAN ${ }^{1}$, ON-YING MAN ${ }^{1}$, HOI-HIN KWOK ${ }^{1}$, LUO CHEN ${ }^{1}$, KING-CHI CHAN ${ }^{1}$, HONG-LOK LUNG ${ }^{1}$, \\ ROGER KAI-CHEONG NGAN ${ }^{2,3}$, RICKY NGOK-SHUN WONG ${ }^{1,2}$, KWOK-WAI LO $^{4}$, ANNE WING-MUI LEE $^{2,5}$, \\ GEORGE SAI-WAH TSAO ${ }^{2,6}$, MICHAEL KAHN ${ }^{7}$, MARIA LI LUNG $^{2,5}$ and NAI-KI MAK ${ }^{1,2}$ \\ ${ }^{1}$ Department of Biology, Hong Kong Baptist University; ${ }^{2}$ Center for Nasopharyngeal Carcinoma Research, \\ University of Hong Kong; ${ }^{3}$ Department of Clinical Oncology, Queen Elizabeth Hospital Hong Kong; \\ ${ }^{4}$ Department of Anatomical and Cellular Pathology, State Key Laboratory of Translational Oncology, \\ The Chinese University of Hong Kong; Departments of ${ }^{5}$ Clinical Oncology and ${ }^{6}$ Anatomy, \\ University of Hong Kong, Hong Kong, P.R. China; ${ }^{7}$ Department of Molecular Medicine, \\ Beckman Research Institute at City of Hope, Duarte, CA 91010, USA
}

Received May 25, 2018; Accepted October 10, 2018

DOI: $10.3892 /$ ijo.2018.4664

\begin{abstract}
The Wnt signaling pathway is known to serve an important role in the control of cell migration. The present study analyzed the mechanisms underlying the in vitro modulation of the migration of nasopharyngeal carcinoma (NPC) cells by the CREB-binding protein/catenin antagonist and Wnt modulator ICG-001. The results revealed that ICG-001-mediated inhibition of tumor cell migration involved downregulated mRNA and protein expression of the Wnt target gene cluster of differentiation (CD)44. It was also demonstrated that ICG-001 downregulated the expression of CD44, and this effect was accompanied by restored expression of microRNA (miRNA)-150 in various NPC cell lines. Using a CD44 3'-untranslated region luciferase reporter assay, miR-150 was confirmed to be a novel CD44-targeting miRNA, which could directly target CD44 and subsequently regulate the migration of NPC cells. The present study provides further insight into the inhibition of tumor cell migration through the modulation of miRNA expression by the Wnt modulator ICG-001.
\end{abstract}

\section{Introduction}

Nasopharyngeal carcinoma (NPC) has a high incidence rate (27.2/100,000 males in 2003) in Southern China (1). Although

Correspondence to: Professor Nai-Ki Mak, Department of Biology, Hong Kong Baptist University, 224 Waterloo Road, Hong Kong, P.R. China

E-mail:nkmak@hkbu.edu.hk

Key words: nasopharyngeal carcinoma, microRNA, cluster of differentiation 44 the majority of primary NPC cases can be successfully treated with radiotherapy, local recurrence and metastatic NPC remain major problems in the treatment of NPC (2). In a preclinical cell model, Lun et al (3) recently demonstrated that a subpopulation of Epstein-Barr virus (EBV) and cluster of differentiation (CD)44-positive NPC cells are resistant to chemotherapy and exhibit properties of cancer stem cells (CSCs). The transmembrane glycoprotein CD44 is primarily considered a multifunctional protein that participates in signaling pathways involved in cancer dissemination (4). The versatility of CD44 in the regulation of cell growth and migration is due to its interaction with various cellular molecules, including ankyrin, ezrin, radixin and moesin (4).

The developmental signaling pathways Wnt, Notch and Hedgehog are known to be used by CSCs to regulate cell growth and differentiation (5). In addition to these stem cell-associated signaling pathways, previous studies also indicate that microRNA (miRNA) $(6,7)$ and epigenetic mechanisms (8-10) serve an important role in the regulation of CSC growth and differentiation. In NPC, it has been recently identified that the CREB-binding protein (CBP)/catenin antagonist and Wnt modulator ICG-001 could inhibit the growth of EBV-positive NPC cells via downregulated expression of the tumor suppressor/pro-differentiator miR-145 (11). It was also observed that ICG-001 reduced the population of cells expressing SRY-box $2^{\mathrm{Hi}} / \mathrm{CD} 44^{\mathrm{Hi}}$ (11). In the present study, the role of miR-150 in the expression of CD44 in ICG-001-treated NPC cells was further demonstrated.

\section{Materials and methods}

Cell culture. The EBV-positive C666-1 NPC cell line was maintained in RPMI-1640 medium (Gibco; Thermo Fisher Scientific, Inc., Waltham, MA, USA) supplemented with $10 \%$ fetal bovine serum (FBS; Gibco; Thermo Fisher 
Scientific, Inc.) and $1 \%$ penicillin-streptomycin (P/S; Gibco; Thermo Fisher Scientific, Inc.). The early passage of NPC xenograft-derived EBV-positive C17 cells (Professor Pierre Busson, Université Paris-Sud, Paris, France) (12) were cultured in RPMI-1640 medium supplemented with 7.5\% FBS, 1\% GlutaMAX (Gibco; Thermo Fisher Scientific, Inc.), $0.2 \%$ Primocin (InvivoGen, San Diego, CA, USA) and $7 \mu \mathrm{M}$ Y-27632 (Cayman Chemical Company, Ann Arbor, MI, USA), an inhibitor of Rho kinases I and II. The EBV-negative HONE-1 NPC cell line was maintained in Dulbecco's modified Eagle's medium (DMEM; Gibco; Thermo Fisher Scientific, Inc.) supplemented with 5\% FBS and 5\% newborn calf serum (Gibco; Thermo Fisher Scientific, Inc.) with $1 \% \mathrm{P} / \mathrm{S}$. The C666-1 and HONE-1 cell lines (13-16) were obtained from the Hong Kong NPC AoE Research Tissue Bank and Cell Line Repository (Hong Kong, China), and were authenticated using an AmpFLSTR Identifier PCR Amplification kit (Thermo Fisher Scientific, Inc.), according to the manufacturer's protocols. To further ensure the HONE-1 cells used in the present study were free from HeLa cell contamination, a single duplex detection polymerase chain reaction (PCR) assay targeting a HeLa-specific L1 retrotransposon insertion, as described by Rahbari et al (17), was conducted, which confirmed that the cell line was not contaminated by HeLA cells. C666-1, C17, and HONE-1 cells were treated with ICG-001 or dimethyl sulfoxide (0.05\%; vehicle control) for 3-7, 3-5 and 5 days, respectively. All cell lines were cultured at $37^{\circ} \mathrm{C}$ in a $5 \% \mathrm{CO}_{2}$ humidified incubator. ICG-001 at $10 \mu \mathrm{M}(1 \mu \mathrm{l} 20 \mathrm{mM}$ stock in 2 ml RPMI-1640 medium (C666-1 and C17 cells) or DMEM (HONE-1 cells), or same volume of DMSO was used for cell treatments unless otherwise specified.

Cell transfection. C666-1 cells $\left(3 \times 10^{5}\right)$ were seeded onto fibronectin-coated $35-\mathrm{mm}$ culture dishes overnight at $37^{\circ} \mathrm{C}$ in a $5 \% \mathrm{CO}_{2}$ humidified incubator. Lipofectamine ${ }^{\circledR} 2000$ (Invitrogen; Thermo Fisher Scientific, Inc.) was then used in all the transient transfection experiments, according to the manufacturer's protocols. In all the siRNA or miRNA transfection studies, $5 \mu 120 \mu \mathrm{M}$ oligonucleotide stocks was added into the culture dishes containing $2 \mathrm{ml}$ RPMI-1640 medium. To investigate the knockdown effect of $\beta$-catenin or CD44, Ambion ${ }^{\mathrm{TM}}$ Silencer ${ }^{\mathrm{TM}}$ Pre-Designed small interfering (si)RNA targeting human $\beta$-catenin (50 nM; Assay ID 146154; Thermo Fisher Scientific, Inc.) or Silencer Select Pre-Designed \& Validated siRNA targeting human CD44 (50 nM; Assay ID s2681; Ambion; Thermo Fisher Scientific, Inc.) was used in parallel with Silencer negative control siRNA (5 0nM; cat. no. AM4611; Ambion; Thermo Fisher Scientific, Inc.;). To investigate the effect of knocking down CBP, ON-TARGETplus SMARTpool Human CBP siRNA (50 nM; cat. no. L-003477-00-0005; GE Healthcare Dharmacon, Inc., Lafayette, CO, USA) was used in parallel with ON-TARGETplus Non-targeting Control siRNA \#1 (50 nM; cat. no. D-001810-01-20; GE Healthcare Dharmacon, Inc.). For miRNA precursor transfection, $50 \mathrm{nM}$ Pre-miR miRNA Precursor mimicking miR-150 precursor (pre-miR-150; Assay ID PM10070; Ambion; Thermo Fisher Scientific, Inc.) was used in parallel with $50 \mathrm{nM}$ Pre-miR miRNA Precursor Negative Control \#1 (Ambion; cat. no. AM17110; Thermo Fisher Scientific, Inc.). To overexpress CD44, 200 ng expression vector pCMV3 with or without the open reading frame of CD44 (cat. no. HG12211-UT; Sino Biological Inc., Beijing, China) was transfected into the cells. After $72 \mathrm{~h}$, the cells were harvested and subjected to subsequent assays.

Transwell migration assay. Transwell inserts $(6.5 \mathrm{~mm})$ with 8.0- $\mu \mathrm{m}$ pore polycarbonate membranes (Corning Incorporated, Corning, NY, USA) were used in the Transwell migration assay. The aforementioned ICG-001-treated or transfected C666-1 cells $\left(2 \times 10^{5}\right)$ were seeded in the upper chamber of the inserts containing RPMI-1640 medium, and the lower chamber contained RPMI-1640 medium supplemented with 10\% FBS. After $24 \mathrm{~h}$ of incubation at $37^{\circ} \mathrm{C}$, the cells remaining on the inserts were removed, while the migrated cells at the bottom of the membrane were fixed in $4 \%$ paraformaldehyde for $15 \mathrm{~min}$ at room temperature, permeabilized in $0.2 \%$ Triton-X for $10 \mathrm{~min}$ at room temperature and stained with DAPI (Sigma-Aldrich; Merck KGaA, Darmstadt, Germany) for $30 \mathrm{~min}$ at room temperature. The cells migrating across the membrane were then visualized under a fluorescence microscope (magnification, $\mathrm{x} 200$ ).

Western blotting. The aforementioned ICG-001-treated or transfected C666-1 or aforementioned ICG-001-treated C17 cells were lysed in lysis buffer [250 mM Tris ( $\mathrm{pH} 8.0$ ), $1 \% \mathrm{NP}-40$ and $150 \mathrm{mM} \mathrm{NaCl}$ ] containing $1 \%$ phosphatase inhibitor cocktail (Calbiochem; Merck KGaA) and $0.25 \%$ protease inhibitors cocktail (Sigma-Aldrich; Merck $\mathrm{KGaA}$ ). Protein concentration was determined with a DC Protein Assay kit (Bio-Rad Laboratories, Inc., Hercules, CA, USA), according to the manufacturer's protocol. Cellular proteins were resolved in SDS-PAGE (5\% gel for CBP detection, and $7.5 \%$ gel for the detection of $\beta$-catenin, CD44, ezrin and $\beta$-actin) and transferred to polyvinylidene fluoride membranes (EMD Millipore, Billerica, MA, USA). The membranes were blocked with $5 \%$ non-fat dry milk in TBS with $0.1 \%$ Tween-20 (TBST) for $1 \mathrm{~h}$ at room temperature, followed by incubation with primary antibodies against $\beta$-catenin (dilution 1:1,000; cat. no. 8480; Cell Signaling Technology, Inc., Danvers, MA, USA), CBP (dilution 1:1,000; cat. no. sc-583; Santa Cruz Biotechnology, Inc., Dallas, CA, USA), CD44 (dilution 1:1,000; cat. no. 3570; Cell Signaling Technology, Inc.), ezrin (dilution 1:1,000; cat. no. 3145; Cell Signaling Technology, Inc.) and $\beta$-actin (dilution 1:5,000; cat. no. A2228; Sigma-Aldrich; Merck KGaA) for $3 \mathrm{~h}$ at room temperature. Subsequently, the membranes were washed with TBST three times (15 min in total) and incubated with corresponding horseradish peroxidase (HRP)-conjugated goat anti-mouse $\operatorname{IgG}(\mathrm{H}+\mathrm{L})$ secondary antibody (dilution 1:5,000; cat. no. 62-6520) or HRP-conjugated goat anti-rabbit IgG $(\mathrm{H}+\mathrm{L})$ secondary antibody (dilution 1:5,000; cat. no. 65-6120 (both from Invitrogen; Thermo Fisher Scientific, Inc.) at room temperature for $1 \mathrm{~h}$. Protein bands were detected with WESTSAVE Up (Western Blotting Substrate) (Lab Frontier Co., Ltd., Seoul, Korea) and visualized on X-ray films (FujiFilm Corporation, Tokyo, Japan) using Carestream Kodak autoradiography GBX fixer/replenisher (Sigma-Aldrich; Merck KGaA). $\beta$-actin was used as the internal control. Band intensities were analyzed using ImageJ software (version 1.46; National Institutes of Health, Bethesda, MD, USA). 
Co-immunoprecipitation (Co-IP) assay. C666-1 cells subjected to Co-IP were lysed in the aforementioned lysis buffer. An anti-CD44 antibody (1:100; cat. no. 3570; Cell Signaling Technology, Inc.) or a nonspecific IgG antibody (1:100; cat. no. 5415; Cell Signaling Technology, Inc.) was allowed to bind with protein G-sepharose (Sigma-Aldrich; Merck $\mathrm{KGaA}$ ) for $1 \mathrm{~h}$ at room temperature, then IP was performed on the cell lysate with the sepharose-associated anti-CD44 or control nonspecific IgG antibodies at $4^{\circ} \mathrm{C}$ overnight. The precipitates were washed with aforementioned lysis buffer and eluted in SDS-sample buffer [0.375 M Tris- $\mathrm{HCl}$ (pH 6.8), 12\% SDS, 60\% glycerol, 6\% 2-mercaptoethanol and $0.025 \%$ bromophenol blue] at $95^{\circ} \mathrm{C}$ for $10 \mathrm{~min}$. Samples were then analyzed by western blotting as aforementioned.

Reverse transcription-quantitative polymerase chain reaction (RT-qPCR) analysis. Total RNA was extracted using TRIzol ${ }^{\circledR}$ reagent (Invitrogen; Thermo Fisher Scientific, Inc.), according to the manufacturer's protocol. To detect CD44 mRNA expression, total RNA of C666-1 cells was reverse transcribed to cDNA using Moloney murine leukemia virus reverse transcriptase kit (cat. no. 28025-013; Invitrogen; Thermo Fisher Scientific, Inc.) with oligo (dT)12-18 primer (cat. no. 18418012; Invitrogen; Thermo Fisher Scientific, Inc.), according to manufacturer's protocols. qPCR was then performed using Power SYBR $^{\circledR}$ Green PCR Master mix (Thermo Fisher Scientific, Inc.) according to the manufacturer's protocol. GAPDH was used as the internal control. The CD44 primer sequences were as follows: Sense, 5'-TCAGAGGAGTAGGAGAGAGGA AAC-3'; and antisense, 5'-GAAAAGTCAAAGTAACAATA ACAGTGG-3' (18). The GAPDH primers were as follows: Sense, 5'-GAAGGTGAAGGTCGGAGTC-3'; and antisense, 5'-GAAGATGGTGATGGGATTTC-3' (19). To detect miR-150 expression of aforementioned ICG-001-treated or transfected C666-1, C17, HONE-1 cells and the C666-1 tumor spheres prepared as subsequently mentioned, a TaqMan ${ }^{\circledR}$ MicroRNA Reverse Transcription kit (Applied Biosystems; Thermo Fisher Scientific, Inc.) was used for RT, according to the manufacturer's protocol, while TaqMan 2X Universal PCR Master mix, no AmpERASE UNG (Applied Biosystems; Thermo Fisher Scientific, Inc.) was used for qPCR. All of the procedures were performed according to manufacturer's protocols. Specific primers for miR-150 were supplied by TaqMan MicroRNA Assays (Assay ID 000473; Applied Biosystems; Thermo Fisher Scientific, Inc.). U6 small nuclear RNA (Assay ID 001093; Applied Biosystems; Thermo Fisher Scientific, Inc.) was used as the internal control. The relative expressions of CD44 and miR-150 transcripts were calculated with the $2^{-\Delta \Delta \mathrm{Cq}}$ method (20).

Tumor sphere formation assay. A tumor sphere formation assay was performed as previously described (8). Briefly, C666-1 cells $\left(2 \times 10^{3}\right.$ cells/well) in DMEM/F12 (Gibco; Thermo Fisher Scientific, Inc.) supplemented with $20 \mathrm{ng} / \mathrm{ml}$ epidermal growth factor (Sigma-Aldrich; Merck KGaA), $20 \mathrm{ng} / \mathrm{ml}$ fibroblast growth factor (Cell Signaling Technology, Inc.) and $20 \mathrm{ng} / \mathrm{ml}$ insulin-like growth factor (Cell Signaling Technology, Inc.) were seeded onto 24-well ultra-low attachment culture plates (Corning Incorporated) for 7 days. Growth factors were added to the cultures every 2-3 days, and the cells were incubated at $37^{\circ} \mathrm{C}$ in a $5 \% \mathrm{CO}_{2}$ humidified incubator. Following incubation, the tumor spheres were observed under an inverted microscope (magnification, x50), the images were captured, and the size of those tumor spheres measuring $>20 \mu \mathrm{m}$ was determined by ImageJ software.

Target gene prediction for miRNA. Potential targets of miR-150 were predicted using the online bioinformatics software TargetScan Human, version 6.2 (http://www.targetscan. org/vert_61/).

Luciferase reporter assay. To investigate the activity of Wnt signaling, C666-1 cells were transfected with the T-cell factor (TCF) reporter plasmid M50 Super 8x TOPFlash $(2 \mu \mathrm{g})$ for $24 \mathrm{~h}$. An internal control vector, pRL-TK (10 ng; Promega Corporation, Madison, WI, USA), was co-transfected into the cells for normalization of the transfection efficiency. Cells were then treated with or without ICG-001 for $24 \mathrm{~h}$. M51 Super 8x FOPFlash (a TOPFlash mutant with mutated TCF sites) was used as a negative control. The firefly luciferase activity of TOPFlash and FOPFlash, and the Renilla luciferase activity of pRL-TK were measured using Dual-Luciferase Reporter Assay system (Promega Corporation) in a microplate luminometer (Tecan Group, Ltd., Mannedorf, Switzerland). The luciferase reporter plasmids M50 Super 8x TOPFlash (cat. no. 12456) and M51 Super 8x FOPFlash (cat. no. 12457) were obtained from Addgene, Inc. (Cambridge, MA, USA). All the transfections were performed in the presence of Lipofectamine 2000 , and the cells were incubated at $37^{\circ} \mathrm{C}$ in a $5 \% \mathrm{CO}_{2}$ humidified incubator.

To investigate the interaction between miR-150 and the 3'-untranslated region (UTR) of CD44 gene transcript, CD44 (NM_000610) Human 3' UTR Clone (wild-type 3'-UTR reporter clones for CD44, wt-CD44 3'UTR) was purchased from OriGene Technologies, Inc. (Rockville, MD, USA), while CD44 3'-UTR mutant constructs with a mutated miR-150 seed region (mut-CD44 3'UTR) were generated using a QuikChange Lightning Multi Site-Directed Mutagenesis kit (Agilent Technologies, Inc., Santa Clara, CA, USA) with the primer 5'-AGATAAATAGCTTCACCCTTTGGGTGTGGGGGGG AAGCATCTGAAAAATTTCTAGAGGGG-3'. The wild-type or mutant CD44 3'-UTR luciferase reporter (50 ng) along with 200 nM miR-150 mimic (Pre-miR-150; Ambion; Thermo Fisher Scientific, Inc.) or miRNA mimic control (Pre-control; Ambion; Thermo Fisher Scientific, Inc.) were transfected into C666-1 cells using Lipofectamine 2000 for 48 h. Prior to cell lysis with the Passive Lysis buffer provided by the Luciferase Assay system (Promega Corporation), the signal of the red fluorescent protein (RFP) transcribed by the vector was determined with a fluorescence microscope (magnification, $\mathrm{x} 10$ ). Subsequently, luciferase activities were measured using the Dual-Luciferase Reporter Assay system (Promega Corporation) in a microplate luminometer and normalized to the signals of RFP.

Immunohistochemical (IHC) staining. A total of 8 female athymic BALB/c nu/nu mice ( 15 g per each) at 6-8 weeks were supplied by the Laboratory Animal Unit of the University of Hong Kong (Hong Kong, China), and housed in sterile rodent micro-isolator systems and given free access to sterile 
A

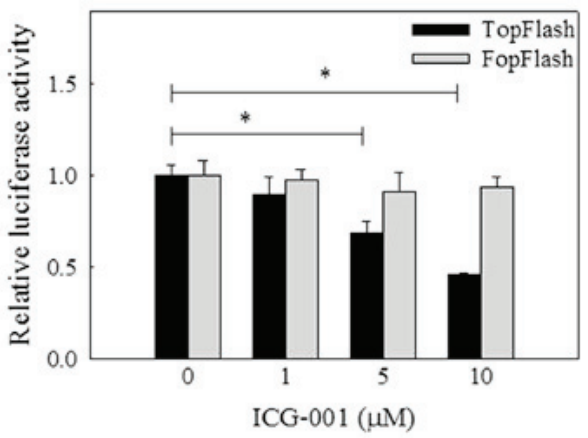

B
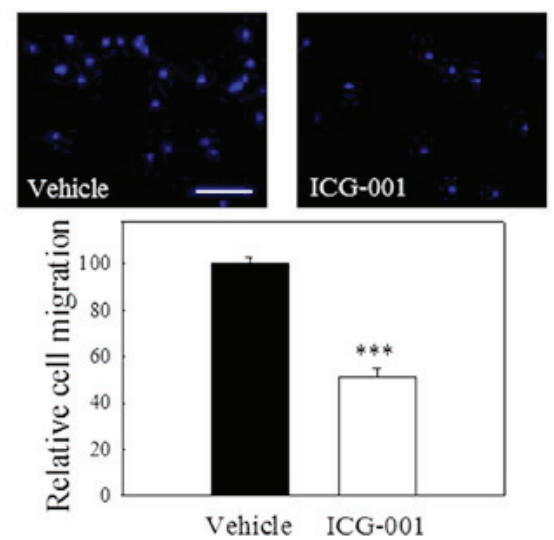

C

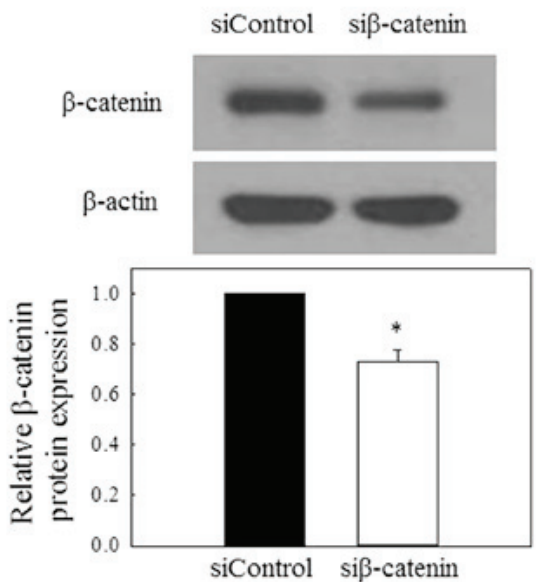

D

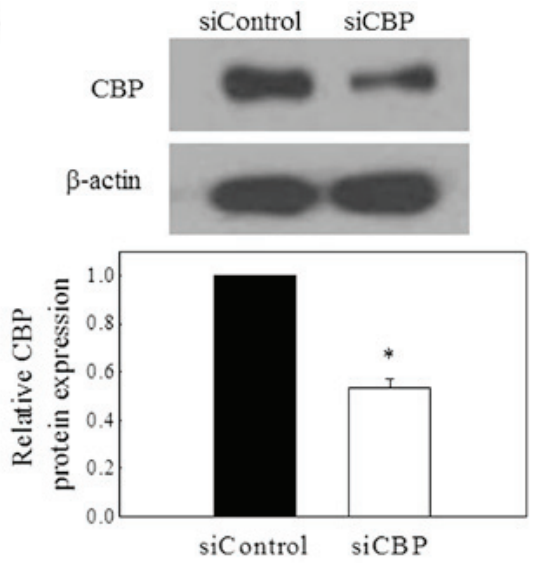

$\mathbf{E}$
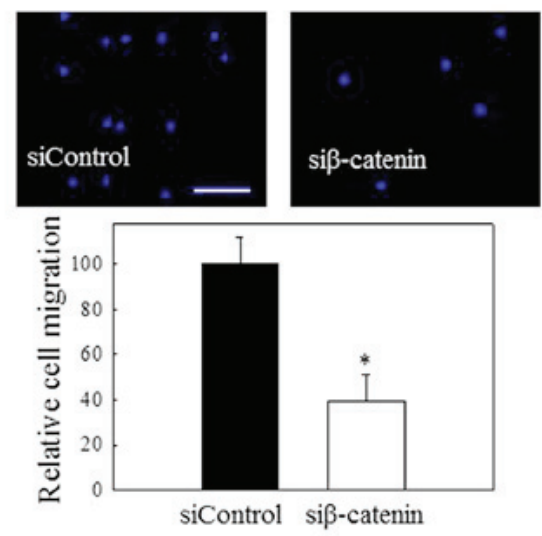

$\mathbf{F}$
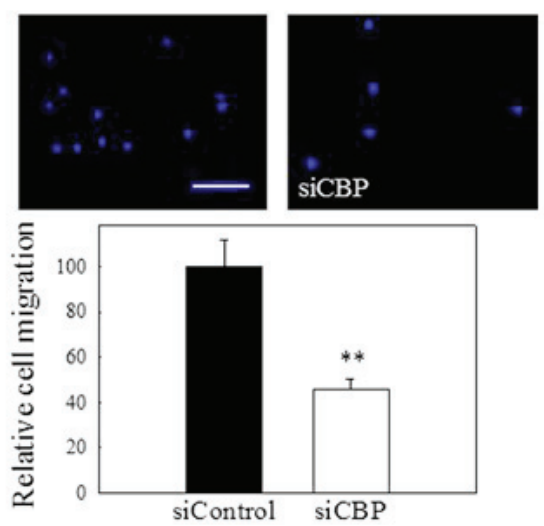

Figure 1. ICG-001 inhibits the migration of nasopharyngeal carcinoma C666-1 cells through $\beta$-catenin/CBP-mediated transcription. (A) Dose-dependent inhibition of TOPFlash luciferase activity by ICG-001 $(0,1,5$ and $10 \mu \mathrm{M})$. The luciferase activity was normalized by the ratio of firefly and Renilla luciferase signals. (B) ICG-001 (10 $\mu \mathrm{M}$ for 7 days) inhibited the migration of C666-1 cells. The migrated cells were stained with DAPI. Representative images are presented. Transfection efficiencies of (C) $\beta$-catenin or (D) CBP siRNA in C666-1 cells were confirmed using western blotting with $\beta$-actin as a control. Representative images of protein bands are depicted, and the band intensities were analyzed using ImageJ software. Quantitative analysis of the inhibition of tumor cell migration upon transfection of the cells with (E) $\beta$-catenin or (F) CBP siRNA. Scale bar, $20 \mu \mathrm{m} .{ }^{*} \mathrm{P}<0.05,{ }^{* *} \mathrm{P}<0.01,{ }^{* * * *} \mathrm{P}<0.001$. CBP, CREB-binding protein; siRNA, small interfering RNA.

water and food by the Department of Clinical Oncology of Queen Elizabeth Hospital Hong Kong (Hong Kong, China). The animal experiment was conducted under license from the Hong Kong Department of Health and approved by the Committee on the Use of Live Animals in Teaching and Research at the University of Hong Kong. According to our previous study, mouse xenograft tumors were generated by injecting C666-1 cells into the nude mice, and the mice were sacrificed by cervical dislocation (11). The xenografts were removed and fixed with $10 \%$ neutral buffered formalin at room temperature for $12 \mathrm{~h}$, and then embedded in paraffin wax. The thickness of the sections was $5 \mu \mathrm{m}$. Heat-induced epitope retrieval at $98^{\circ} \mathrm{C}$ was performed in $10 \mathrm{mM}$ sodium citrate buffer (Sigma-Aldrich; Merck KGaA). The tissues were blocked with $10 \%$ goat serum (Sigma-Aldrich; Merck $\mathrm{KGaA}$ ) and $1 \%$ bovine serum albumin (Affymetrix; Thermo Fisher Scientific, Inc.) in PBS for 30 min at room temperature, followed by staining with an anti-CD44 antibody (overnight incubation at room temperature; dilution, 1:100), polyclonal goat anti-mouse biotinylated $\operatorname{IgG}(1.5 \mathrm{~h}$ incubation at room temperature; dilution 1:300; cat. no. E043301; Dako; Agilent Technologies, Inc.) and streptavidin/HRP (45 min incubation at room temperature; dilution 1:300; cat. no. P039701-2; Dako; Agilent Technologies, Inc.). The staining signals were 
A

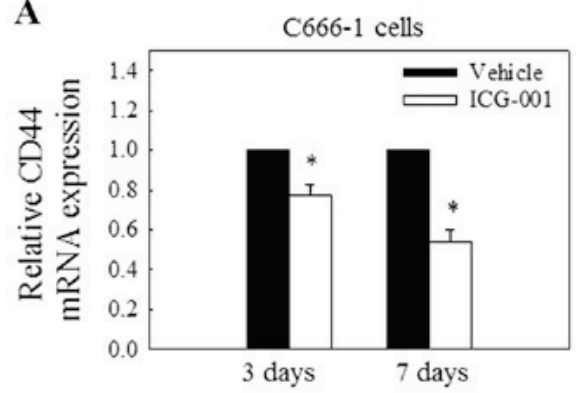

B
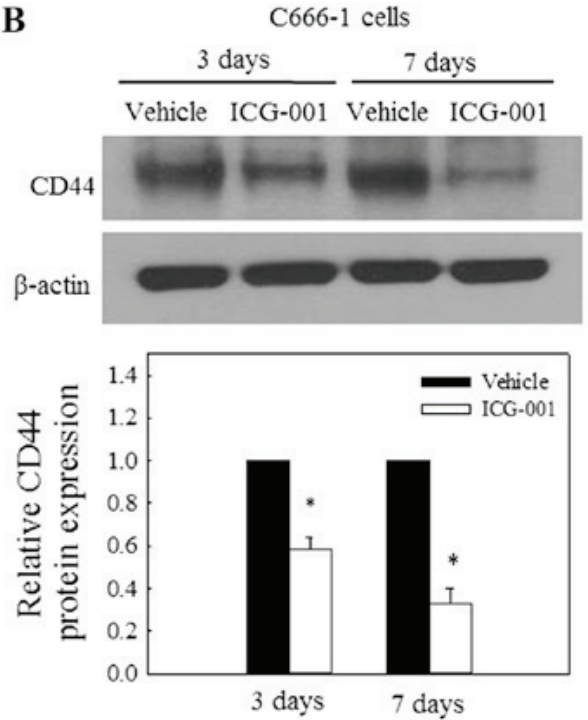

C

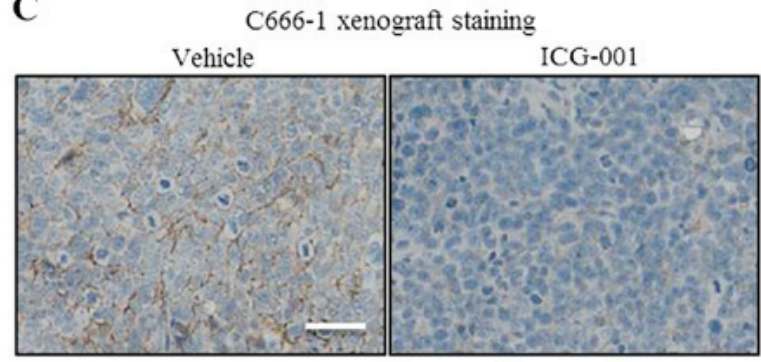

D
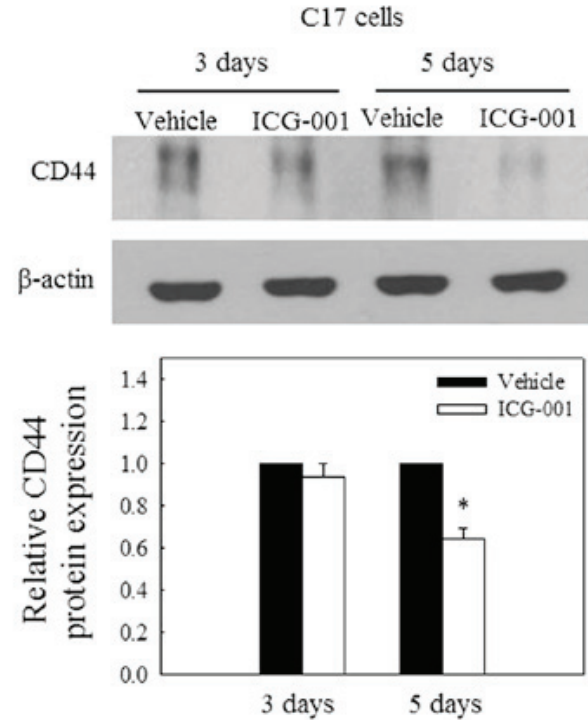

Figure 2. ICG-001 inhibits the expression of CD44 in NPC cells. ICG-001 inhibited the (A) mRNA and (B) protein expression of CD44 in C666-1 cells. (C) ICG-001 inhibited the expression of CD44 in the tumor tissues of C666-1 xenografts. (D) ICG-001 reduced the expression of CD44 in Epstein-Barr virus-positive NPC C17 cells. Scale bar, $10 \mu \mathrm{m}$. ${ }^{*} \mathrm{P}<0.05$, compared with the vehicle control. CD44, cluster of differentiation 44; NPC, nasopharyngeal carcinoma.

visualized using 3,3'-diaminobenzidine tetrahydrochloride hydrate (Sigma-Aldrich; Merck KGaA). The sections were counterstained with hematoxylin (5 $\mathrm{min}$ at room temperature) (Sigma-Aldrich; Merck KGaA) and the images were captured under an inverted microscope (magnification, $\mathrm{x} 400$ ). The CD44 staining intensity was analyzed by Spectrum version 11.1.1.765 software (Aperio Technologies, Vista, CA, USA).

Statistical analysis. Data are presented as the mean \pm standard deviation of $\geq 3$ independent experiments. The difference between control and treatment groups was determined by one-way analysis of variance followed by Holm-Sidak comparison method using SigmaPlot Version 12.0 (Systat Software, Inc., San Jose, CA, USA). P $<0.05$ was considered to indicate a statistically significant difference.

\section{Results}

ICG-001 inhibits canonical Wnt signaling in NPC cells. ICG-001 is a small molecule, CBP antagonist capable of modulating Wnt-mediated $\beta$-catenin transcription. Thus, the present study first confirmed the effect of ICG-001 on TCF reporter activity in C666-1 NPC cells. The results depicted in Fig. 1A indicate that ICG-001 could significantly reduce the luminescent signal of the TOPFlash reporter, but not that of the FOPFlash reporter, which contains mutated TCF sites. This observation indicated that ICG-001 could antagonize
$\beta$-catenin/TCF transcription in our cell model. Together with a group of previously reported Wnt target genes that are downregulated by ICG-001 in C666-1 cells (11), it was confirmed that ICG-001 specifically inhibited the canonical Wnt signaling pathway in NPC cells.

ICG-001 inhibits the migration of NPC cells. Our group previously demonstrated that ICG-001 could restore the expression of the tumor suppressor miR-145 and inhibit the growth of CSC-enriched NPC spheroid cells (11). The present study further revealed that ICG-001 could significantly inhibit the migration of NPC cells in a Transwell migration assay (Fig. 1B). Since ICG-001 is capable of interfering with the $\beta$-catenin/CBP downstream signaling, it was hypothesized that siRNA silencing of $\beta$-catenin or CBP expression could also inhibit the migration of NPC cells. The present results demonstrated that siRNA knockdown of the protein expression of $\beta$-catenin (Fig. 1C) or CBP (Fig. 1D) resulted in significantly reduced migration of NPC cells (Fig. 1E and F). These observations indicate that $\beta$-catenin and CBP are involved in the regulation of migration of NPC cells.

Involvement of CD44 in the migration of NPC cells. The expression of CD44 has previously been demonstrated to be regulated by $\mathrm{Wnt} / \beta$-catenin signaling (21). In the present study, the expression of CD44 was determined in ICG-001-treated NPC cells. The results depicted in Fig. 2A 
A

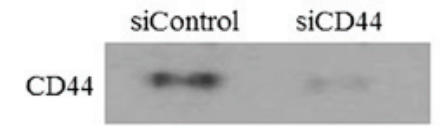

$\beta$-actin

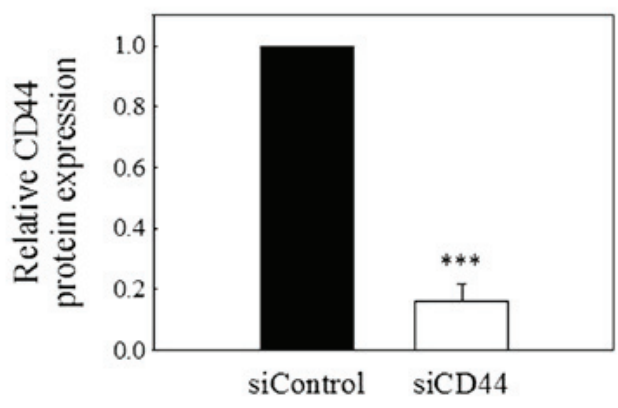

B
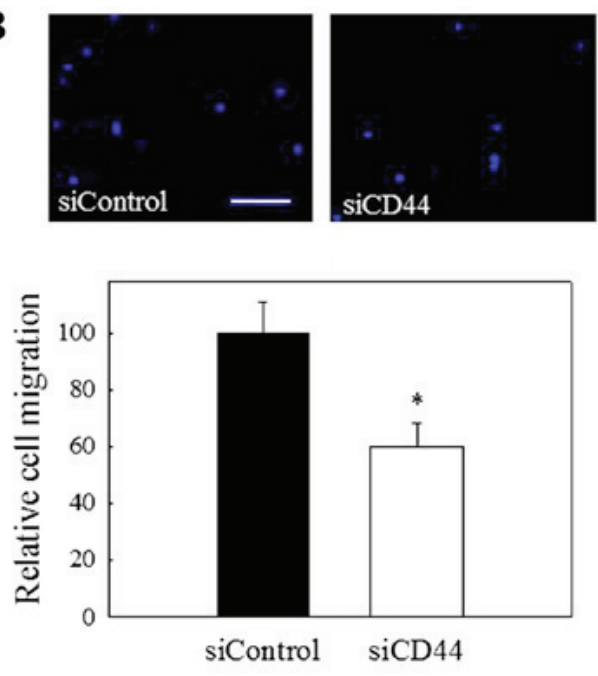

C

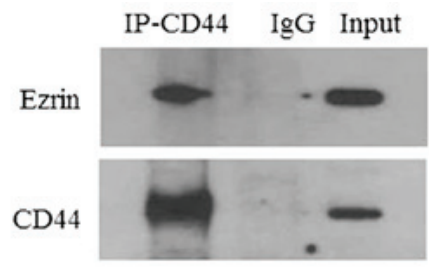

D
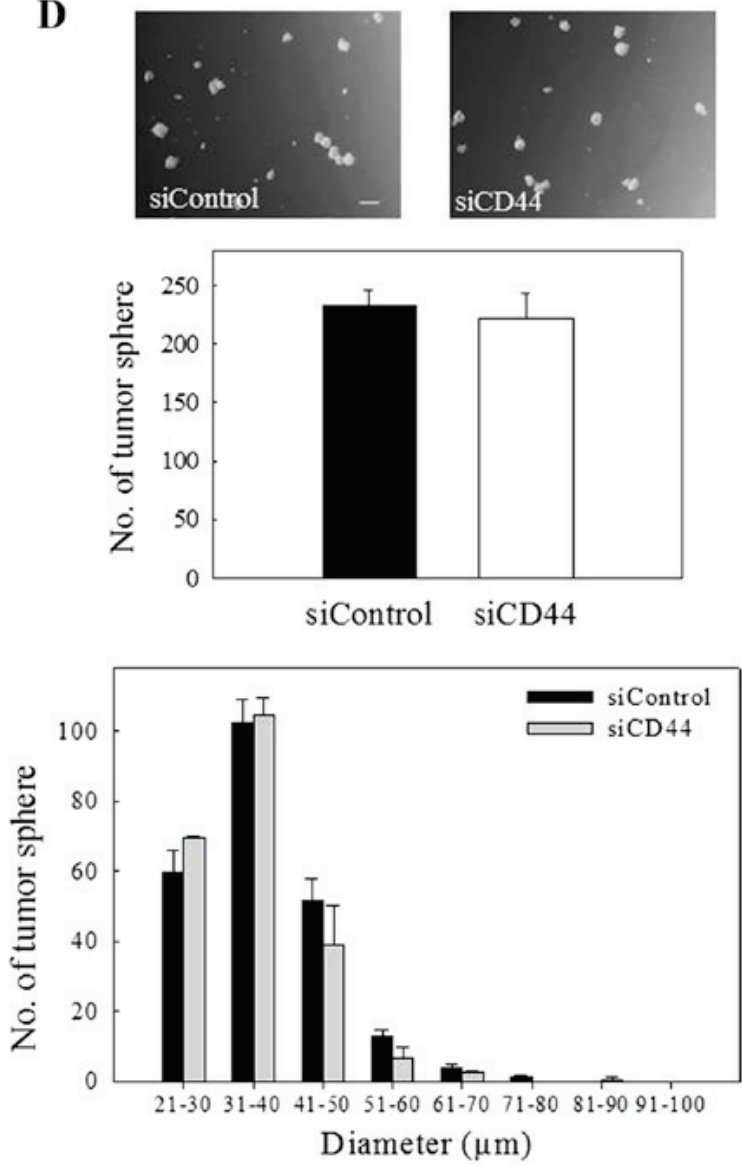

Figure 3. Involvement of CD44 in the ICG-001-mediated inhibition of migration of nasopharyngeal carcinoma cells. (A) The transfection efficiency of CD44 siRNA in C666-1 cells was confirmed by western blotting with $\beta$-actin as a control. (B) CD44 siRNA treatment reduced the number of migrating cells, as demonstrated with a Transwell migration assay. Scale bar, $20 \mu \mathrm{m}$. (C) Co-IP of CD44 and ezrin. Total cell lysate was immunoprecipitated with an anti-CD44 antibody and then detected using anti-ezrin and anti-CD44 antibodies in western blotting. (D) CD44 siRNA treatment had no significant effect on the number or size of tumor spheres formed in the tumor sphere formation assay. Upper panel, number of tumor spheres. Lower panel, size distribution of the tumor spheres. Scale bar, $100 \mu \mathrm{m} .{ }^{*} \mathrm{P}<0.05,{ }^{* * *} \mathrm{P}<0.001$. CD44, cluster of differentiation 44; siRNA, small interfering RNA; IP, immunoprecipitation.

and $B$ indicate that ICG-001 significantly inhibited the mRNA and protein expression of CD44 in C666-1 cells. To further confirm the effect of ICG-001 on the expression of CD44 in tumor tissues, IHC staining of CD44 was performed on tumor tissues obtained from C666-1 tumor-bearing nude mice treated with ICG-001 or untreated. The results from Fig. 2C indicated reduced immunoreactivity of CD44 in the tumor tissues obtained from ICG-001-treated animals. Additionally, the effect of ICG-001 on the protein expression of CD44 was also significantly reduced in EBV-positive NPC C17 cells (Fig. 2D). These results indicated that ICG-001 could downregulate the expression of CD44 in various NPC cell lines.

To confirm the involvement of CD44 in the migration of NPC cells, the expression of CD44 was knocked down by transfection of the NPC cells with CD44 siRNA. The results depicted inFig.3Arevealed thatCD44 siRNA could significantly reduce the protein expression of CD44, and this effect was accompanied by a significant reduction in the migration of NPC cells (Fig. 3B). Ezrin is a key molecule associating the plasma membrane components with the cytoskeleton, and its association with CD44 is particularly important in mediating cell migration $(22,23)$. To further confirm the interaction of CD44 with ezrin in NPC cells, Co-IP was performed using total cell lysates. The results of Fig. $3 \mathrm{C}$ revealed Co-IP between CD44 and ezrin, indicating that CD44 interacts with the aforementioned migration-regulatory components in NPC cells. Notably, the capability of CD44 siRNA-transfected cells to form tumor spheres was not significantly different to that of control siRNA-transfected cells (Fig. 3D), indicating that CD44 is not involved in the growth of C666-1 tumor spheres. Collectively, the results from these experiments indicate that CD44 is involved in the regulation of the migration of NPC cells. 

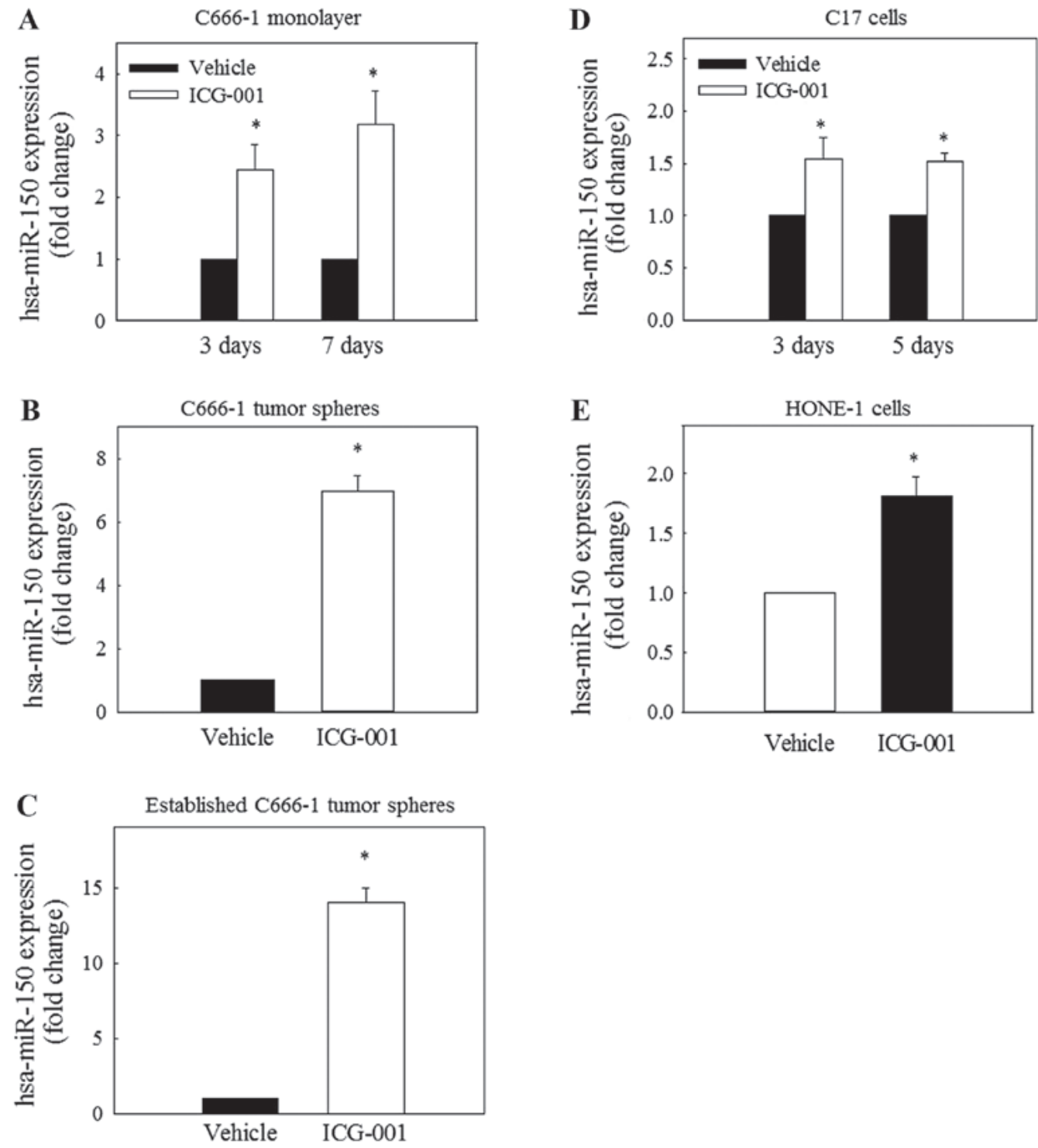

Figure 4. RT-qPCR analysis of the expression level of miR-150 in ICG-001-treated C666-1 cells under (A) monolayer (3 and 7 days) and (B) tumor sphere culture conditions (7 day). (C) C666-1 cells were allowed to grow for 7 days and form tumor spheres under tumor sphere culture conditions. The established tumor spheres were then treated with ICG-001 $(10 \mu \mathrm{M})$ for an additional 7 days. (D) Expression levels of miR-150 in ICG-001-treated (3 and 5 days) EBV-positive C17 cells derived from C17 xenografts. (E) Expression level of miR-150 in ICG-001-treated (5 days) EBV-negative HONE-1 cells. ICG-001 $(10 \mu \mathrm{M})$ was applied in these RT-qPCR analyses. "P<0.05, compared with the vehicle control. RT-qPCR, reverse transcription-quantitative polymerase chain reaction; miR, microRNA; EBV, Epstein-Barr virus.

ICG-001 restores the expression of miR-150. A recent study on miRNA expression demonstrated that the expression level of miR-150 is reduced in NPC tissues (24). To evaluate the possible involvement of miR-150 in the ICG-001-mediated inhibition of CD44 expression, the expression of miR-150 was determined in C666-1 cells under monolayer and spheroid culture conditions. The results in Fig. 4A-C revealed that ICG-001 could significantly restore miR-150 expression under these culture conditions. Significantly restored expression of miR-150 was also observed in EBV-positive C17 (Fig. 4D) and EBV-negative HONE-1 (Fig. 4E) NPC cells.

It has been previously reported that the HONE-1 cell line appears to be a part of the HeLa genomic sequence, indicating that it may be a derivative of HeLa cervical carcinoma cells and another cell line of unknown origin (25). To ensure that the HONE-1 cells used in the present study were not contaminated by HeLa cells, a single duplex detection PCR assay was performed. The results revealed that no L1 insertion was detected in HONE-1 cells, indicating that the HONE-1 cells used in the present study are not likely to be cross-contaminated with HeLa cells (data not shown).

$C D 44$ is a direct target of $m i R-150$. In addition to the reduced expression of CD44 mRNA, the present study sought to examine whether additional mechanisms are also involved in the downregulated expression of CD44 in ICG-001-treated NPC cells. To determine the possible involvement of miRNA in the expression of CD44, the impact of overexpression of miR-150 on the protein expression of CD44 was evaluated. Fig. 5A demonstrates that C666-1 cells could be efficiently transfected with pre-miR-150. Subsequently, a significant reduction in CD44 protein expression was observed in pre-miR-150-transfected cells (Fig. 5B), indicating that miR-150 may be involved in the ICG-001-induced 
A

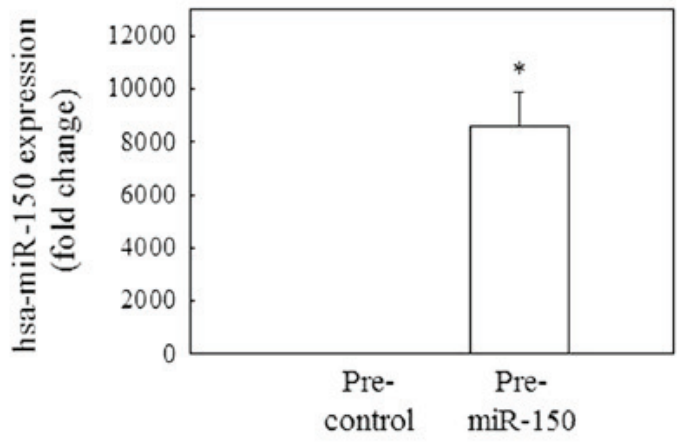

B

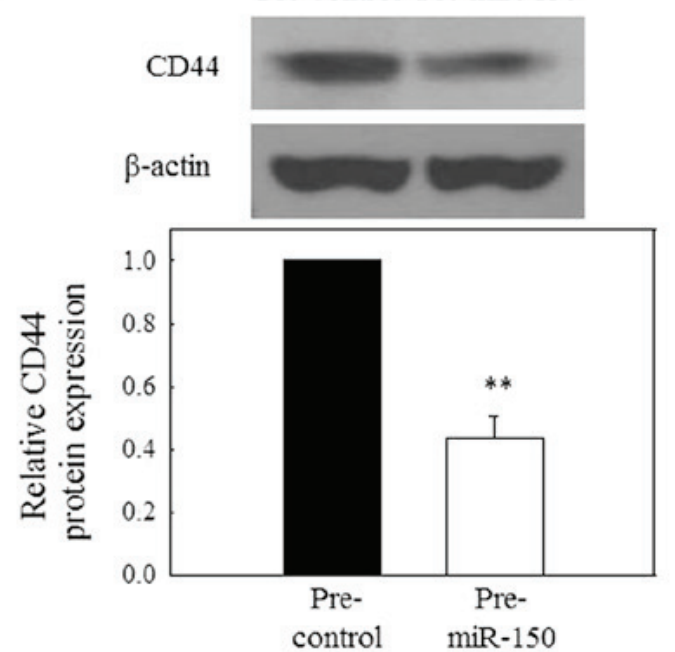

C

CD44 3'Utr ...UUUUUdagaugcudcuggGagac... 3'

111111

hsa-miR-150 GUGACCAUGUUCCCAACCCUCU 5

CD44 3'UtR mutant ...UUUUUCAgaugcuUCUGGGaGAC... 3'

$\star \star \star \star \star \star \star *$

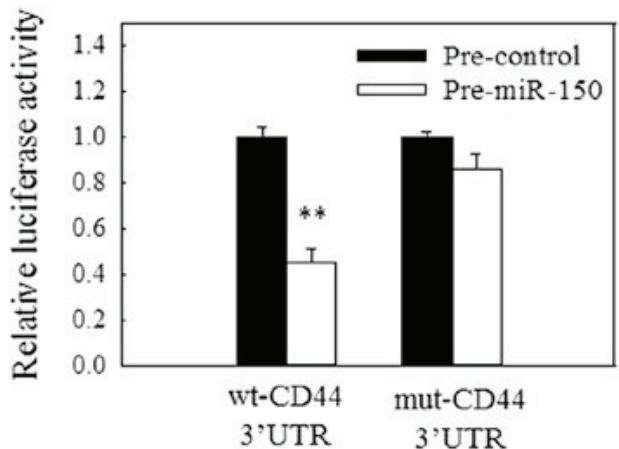

D

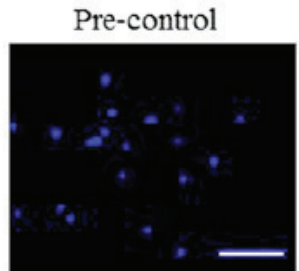

Pre-control + pCMV3-CD44
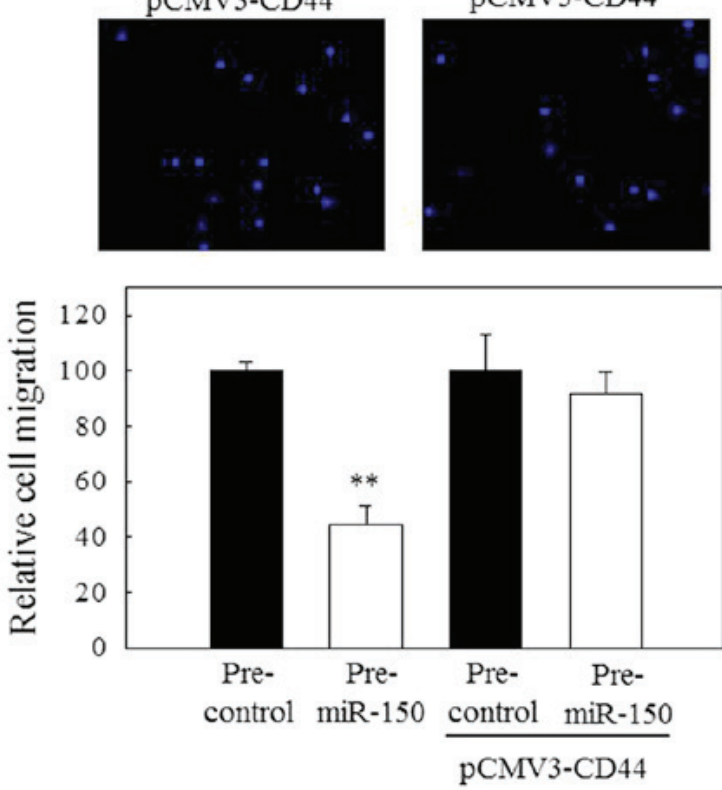

$\mathbf{E}$

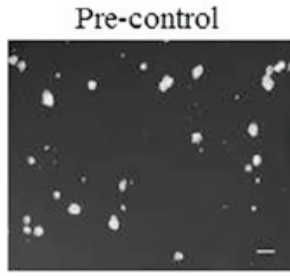

Pre-miR-150
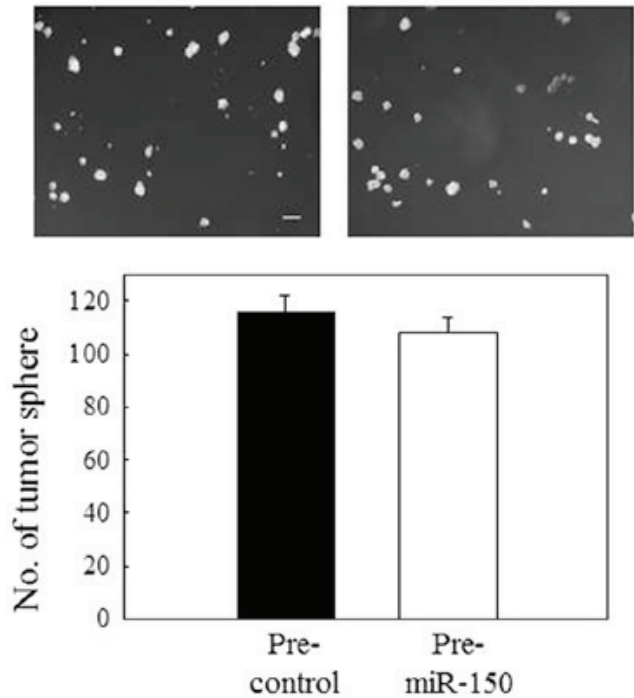

Figure 5. The miR-150/CD44 axis is involved in the regulation of nasopharyngeal carcinoma cell migration. (A) The transfection efficiency of pre-miR-150 at $50 \mathrm{nM}$ in C666-1 cells was confirmed by reverse transcription-quantitative polymerase chain reaction. (B) Pre-miR-150 (50 nM) inhibited the protein expression of CD44. (C) A putative binding site of miR-150 on CD44 mRNA 3'-UTR was first predicted using TargetScan. Subsequently, C666-1 cells were co-transfected with $200 \mathrm{nM}$ pre-miR-150 or $200 \mathrm{nM}$ pre-control and $50 \mathrm{ng}$ wt-CD44 3'-UTR reporter vector or $50 \mathrm{ng}$ mut-CD44 3'-UTR reporter vector Luciferase activity was normalized to the red fluorescence protein signal, and representative images are depicted. (D) Overexpression of miR-150 (50 nM) resulted in the inhibition of migration of C666-1 cells, but this inhibitory effect was attenuated when the cells were treated with pre-miR-150 (50 nM) and pCMV-CD44 (200 ng). Scale bar, $20 \mu \mathrm{m}$. (E) Treatment with pre-miR-150 $(50 \mathrm{nM})$ had no significant effect on the growth of tumor spheres. Scale bar, $100 \mu \mathrm{m}$. ${ }^{*} \mathrm{P}<0.05$ and ${ }^{* *} \mathrm{P}<0.01$, compared with pre-control. miR, microRNA; CD44, cluster of differentiation 44; pre-miR, precursor miR; pre-control, precursor control miR; 3'-UTR, 3'-untranslated region; wt, wild-type; mut, mutant.

downregulated expression of CD44 in NPC cells. Based on the prediction results from TargetScan, miR-150 potentially targets the 3'-UTR of CD44 mRNA (Fig. 5C, upper panel).
To further confirm the specific action of miR-150, a 3'-UTR reporter assay was used to verify the targeting of the 3'UTR of CD44 mRNA by miR-150. For that purpose, C666-1 cells 
were transfected with a wild-type or mutant CD44 3'-UTR reporter together with a pre-miR-150 (miR-150 mimic) or a miRNA mimic control. The results in the lower panel of Fig. 5C revealed that miR-150 could significantly reduce the wild-type 3'-UTR reporter activity, whereas the effect of miR-150 on the mutant 3'-UTR was not significant. These observations indicate that CD44 is a novel target of miR-150 in NPC cells. In a functional study, transfection of C666-1 cells with pre-miR-150 resulted in a significant reduction in the migration of tumor cells (Fig. 5D). Furthermore, this inhibitory effect could be attenuated when the cells were transfected with pre-miR-150 and pCMV-CD44.

miR-150 overexpression inhibits tumor cell migration but not spheroid growth. As aforementioned, siRNA knockdown of CD44 only inhibited the migration but not the growth of NPC tumor spheres. In the present study, two biological assays, spheroid formation and tumor cell migration assays, were then used to further evaluate the functional implication of the miR-150/CD44 axis in NPC cells. NPC cells were transfected with the pre-miR-150. The results in Fig. 5D revealed that the migratory activity of pre-miR-150-transfected NPC cells was significantly reduced, compared with the control-transfected cells. However, exogenous miR-150 had no significant effect on the formation of tumor spheres (Fig. 5E). Collectively, these data indicate that the miR-150/CD44 axis is involved in the regulation of NPC cell migration.

\section{Discussion}

CD44 is a cell surface membrane molecule involved in the regulation of diverse functions, including migration, matrix assembly, apoptosis resistance and drug resistance, in tumor cells in a context-dependent manner (4). It has previously been demonstrated that CD44 may interact with hyaluronic acid and stimulate the proliferation of endothelial cells (26). In colon cancer, CD44 has been indicated to regulate the in vitro and in vivo growth of xenografts in animals (27). CD44 has also been implicated in the self-renewal and maintenance of pluripotency (4). Another well-known function of CD44 is the regulation of tumor cell migration via interaction with ezrin (28). In NPC, an association between the expression of CD44 and the characteristics of the epithelial-mesenchymal transition (EMT) has previously been reported (29). However, the biological function of CD44 in NPC cells has not been fully examined to date. In view of the importance of CD44 in the regulation of tumor cell activities, the present study sought to further examine the underlying mechanisms of ICG-001-induced downregulation of CD44 expression in NPC cells.

An association between ICG-001-mediated inhibition of in vitro migration of NPC cells and downregulated expression of CD44 at the mRNA and protein level was observed. ICG-001 is a CBP antagonist that has previously been demonstrated to block the interaction between $\beta$-catenin and $\mathrm{CBP}$, and to inhibit the downstream transcription of a subset of Wnt target genes (30). The reduced expression of CD44 mRNA observed in the present study could be explained by the fact that CD44 is a well-known Wnt downstream target gene (31). Notably, a significant increase in the expression of miR-150 was also observed in ICG-001-treated NPC cells. Previous studies demonstrated that miR-150 is one of the miRNAs downregulated in NPC $(24,32)$. Further bioinformatics analysis using TargetScan indicated that CD44 is a predicted target of miR-150. Using the CD44 3'-UTR luciferase reporter assay, the present study confirmed that CD44 is a novel target of miR-150. This observation indicated that the restored expression of miR-150 may be an additional mechanism contributing to the reduced protein expression of CD44 in ICG-001-treated NPC cells.

Regarding the biological functions of miR-150 in tumorigenesis, previous studies demonstrated that the expression of miR-150 is significantly reduced in various tumor types, including colon cancer (33), chronic myeloid leukemia (34), acute lymphocytic leukemia (35), mantle cell lymphoma (36), Burkitt lymphoma (BL) (37), gastric cancer (38), esophageal squamous cell carcinoma (39) and natural killer (NK)/T-cell lymphoma (40). In BL, re-expression of miR-150 inhibited tumor cell proliferation and induced the differentiation of tumor cells by targeting c-Myb (41). The involvement of the miR-150/Myb axis in the regulation of tumor cell differentiation was also demonstrated in myeloid leukemia (35). In NK/T-cell lymphoma, overexpression of miR-150 resulted in the inhibition of tumor cell proliferation and induction of apoptosis through downregulated expression of Dyskeratosis congenita 1 and RAC- $\beta$ serine/threonine-protein kinase (40). In esophageal squamous cell carcinoma, the tumor-suppressive activity of miR-150 was attributed to its capacity to target the EMT inducer Zinc finger E-box-binding homeobox 1 (39). These observations indicate that miR-150 acts as a tumor suppressor in a number of tumor types, and its effect is cellular context-dependent. A previous study demonstrated that the reduced level of miR-150 expression could be due to promoter methylation (42). In the preliminary study, the status of methylation of miR-150 promoter was examined. However, a significant change of the methylation status of the promoter was not observed following ICG-001 treatment. The mechanistic action of miR-150 remains under investigation.

In the present study, a novel function of miR-150 was identified in its capacity to target CD44 and inhibit the migration of NPC cells. This observation was further supported by the results of the Co-IP/western blotting assay, which revealed that CD44 co-precipitates with ezrin, an important cytoplasmic component known to be associated with the migration-controlling machinery in the cytoplasm $(22,23)$. This result is reminiscent of the previous observation by Endo et al (43) that overexpression of the EBV protein Latent membrane protein 1 (LMP-1) in NPC cells could activate ezrin and the subsequent linking of ezrin with CD44. Furthermore, IHC analysis of 200 NPC tissues revealed that increased expression of ezrin was associated with an increased rate of lymph node metastasis (44). A similar observation was also previously reported in EBV-associated gastric carcinoma with lymphoid stroma (GCLS), where high levels of ezrin in GCLS were associated with lymph node metastasis (45). The importance of CD44 and ezrin has also recently been demonstrated in breast cancer (23). Donatello et al (23) reported that CD44 and ezrin are localized in different membrane locations in non-migrating cells. Under migration-stimulating conditions, CD44 binds to ezrin and 
regulates the migration of breast tumor cells (23). Collectively, these data indicate that LMP-1/ezrin/CD44 serve an important role in the promotion of NPC cell migration, and ICG-001 may have an anti-migratory function through the restoration of the expression of the tumor suppressor miR-150 in NPC cells.

ICG-001 is a CBP antagonist targeting the Wnt signaling pathway (46). In the present study, ICG-001 was observed to disrupt $\beta$-catenin/CBP/Wnt signaling-mediated tumor cell migration via the miR-150/CD44 axis in NPC cells. The present study also reported a novel function of miR-150 in NPC cells. Together with our previous observations (11), the present results indicate that therapeutic intervention of the Wnt signaling pathway with this CBP antagonist may be a strategy for inhibiting the growth and dissemination of NPC tumor cells.

\section{Acknowledgements}

The authors would like to thank Miss Carman Lo (Department of Anatomical and Cellular Pathology, State Key Laboratory in Oncology in South China, The Chinese University of Hong Kong, Hong Kong, China) for the maintenance of NPC xenograft-derived EBV-positive C17 NPC cells.

\section{Funding}

The present project was supported by the Research Grants Council of the Hong Kong Special Administrative Region for the NPC Area of Excellence (grant no. AoE/M 06/08 Center for Nasopharyngeal Carcinoma Research) and the Strategic Development Fund (grant no. HKBU SDF 15-1012-P04) of Hong Kong Baptist University.

\section{Availability of data and materials}

The datasets used and/or analyzed during the current study are available from the corresponding author on reasonable request.

\section{Authors' contributions}

LSC, OYM, HHK, LC and KCC were involved in the in vitro and in vivo studies. HLL, RKCN, RNSW, KWL, AWML, GSWT, MK, MLL and NKM were involved in the project design and data analysis. LSC and NKM wrote the manuscript. All authors have read and approved the final manuscript.

\section{Ethics approval and consent to participate}

For the C666-1 xenograft study, nude mice were supplied by the Laboratory Animal Unit of the University of Hong Kong (Hong Kong, China) and housed by the Department of Clinical Oncology of Queen Elizabeth Hospital Hong Kong (Hong Kong, China). The animal experiment was conducted under license from the Hong Kong Department of Health and approved by the Committee on the Use of Live Animals in Teaching and Research at the University of Hong Kong.

\section{Patient consent for publication}

Not applicable.

\section{Competing interests}

The authors declare that they have no competing interests.

\section{References}

1. Cao SM, Simons MJ and Qian CN: The prevalence and prevention of nasopharyngeal carcinoma in China. Chin J Cancer 30: 114-119, 2011.

2. Lee AW, Ma BB, Ng WT and Chan AT: Management of nasopharyngeal carcinoma: Current practice and future perspective. J Clin Oncol 33: 3356-3364, 2015.

3. Lun SW, Cheung ST, Cheung PF, To KF, Woo JK, Choy KW, Chow C, Cheung CC, Chung GT, Cheng AS, et al: CD44+ cancer stem-like cells in EBV-associated nasopharyngeal carcinoma. PLoS One 7: e52426, 2012.

4. Zöller M: CD44: Can a cancer-initiating cell profit from an abundantly expressed molecule? Nat Rev Cancer 11: 254-267, 2011.

5. Takebe N, Miele L, Harris PJ, Jeong W, Bando H, Kahn M, Yang SX and Ivy SP: Targeting Notch, Hedgehog, and Wnt pathways in cancer stem cells: Clinical update. Nat Rev Clin Oncol 12: 445-464, 2015.

6. Garofalo $\mathrm{M}$ and Croce CM: Role of microRNAs in maintaining cancer stem cells. Adv Drug Deliv Rev 81: 53-61, 2015.

7. Wang ZM, Du WJ, Piazza GA and Xi Y: MicroRNAs are involved in the self-renewal and differentiation of cancer stem cells. Acta Pharmacol Sin 34: 1374-1380, 2013.

8. Ravasio R, Ceccacci E and Minucci S: Self-renewal of tumor cells: Epigenetic determinants of the cancer stem cell phenotype. Curr Opin Genet Dev 36: 92-99, 2016.

9. Avgustinova A and Benitah SA: The epigenetics of tumour initiation: Cancer stem cells and their chromatin. Curr Opin Genet Dev 36: 8-15, 2016.

10. Muñoz P, Iliou MS and Esteller M: Epigenetic alterations involved in cancer stem cell reprogramming. Mol Oncol 6: 620-636, 2012.

11. Chan KC, Chan LS, Ip JC, Lo C, Yip TT, Ngan RK, Wong RN, Lo KW, Ng WT, Lee AW, et al: Therapeutic targeting of $\mathrm{CBP} / \beta$-catenin signaling reduces cancer stem-like population and synergistically suppresses growth of EBV-positive nasopharyngeal carcinoma cells with cisplatin. Sci Rep 5: 9979, 2015.

12. Busson P, Ganem G, Flores P, Mugneret F, Clausse B, Caillou B, Braham K, Wakasugi H, Lipinski M and Tursz T: Establishment and characterization of three transplantable EBV-containing nasopharyngeal carcinomas. Int J Cancer 42: 599-606, 1988.

13. Glaser R, Zhang HY, Yao KT, Zhu HC, Wang FX, Li GY, Wen DS and Li YP: Two epithelial tumor cell lines (HNE-1 and HONE-1) latently infected with Epstein-Barr virus that were derived from nasopharyngeal carcinomas. Proc Natl Acad Sci USA 86: 9524-9528, 1989.

14. Yao KT, Zhang HY, Zhu HC, Wang FX, Li GY, Wen DS, Li YP, Tsai $\mathrm{CH}$ and Glaser R: Establishment and characterization of two epithelial tumor cell lines (HNE-1 and HONE-1) latently infected with Epstein-Barr virus and derived from nasopharyngeal carcinomas. Int J Cancer 45: 83-89, 1990.

15. Cheng Y, Ho RL, Chan KC, Kan R, Tung E, Lung HL, Yau WL, Cheung AK, Ko JM, Zhang ZF, et al: Anti-angiogenic pathway associations of the 3p21.3 mapped BLU gene in nasopharyngeal carcinoma. Oncogene 34: 4219-4228, 2015.

16. Chai AW, Cheung AK, Dai W, Ko JM, Ip JC, Chan KW, Kwong DL, Ng WT, Lee AW, Ngan RK, et al: Metastasis-suppressing NID2, an epigenetically-silenced gene, in the pathogenesis of nasopharyngeal carcinoma and esophageal squamous cell carcinoma. Oncotarget 7: 78859-78871, 2016.

17. Rahbari R, Sheahan T, Modes V, Collier P, Macfarlane C and Badge RM: A novel L1 retrotransposon marker for HeLa cell line identification. Biotechniques 46: 277-284, 2009.

18. Peterson LF, Wang Y, Lo MC, Yan M, Kanbe E and Zhang DE: The multi-functional cellular adhesion molecule CD44 is regulated by the $8 ; 21$ chromosomal translocation. Leukemia 21 : 2010-2019, 2007.

19. Lo MC, Yip TC, Ngan KC, Cheng WW, Law CK, Chan PS, Chan KC, Wong CK, Wong RN, Lo KW, et al: Role of MIF/CXCL8/CXCR2 signaling in the growth of nasopharyngeal carcinoma tumor spheres. Cancer Lett 335: 81-92, 2013.

20. Livak KJ and Schmittgen TD: Analysis of relative gene expression data using real-time quantitative PCR and the 2(-Delta Delta C(T)) Method. Methods 25: 402-408, 2001. 
21. Wielenga VJ, Smits R, Korinek V, Smit L, Kielman M, Fodde R, Clevers $\mathrm{H}$ and Pals ST: Expression of CD44 in Apc and Tcf mutant mice implies regulation by the WNT pathway. Am J Pathol 154: 515-523, 1999.

22. Bretscher A, Reczek D and Berryman M: Ezrin: A protein requiring conformational activation to link microfilaments to the plasma membrane in the assembly of cell surface structures. J Cell Sci 110: 3011-3018, 1997.

23. Donatello S, Babina IS, Hazelwood LD, Hill AD, Nabi IR and Hopkins AM: Lipid raft association restricts CD44-ezrin interaction and promotion of breast cancer cell migration. Am J Pathol 181: 2172-2187, 2012

24. Wang S, Mo Y, Midorikawa K, Zhang Z, Huang G, Ma N, Zhao W, Hiraku Y, Oikawa S and Murata M: The potent tumor suppressor miR-497 inhibits cancer phenotypes in nasopharyngeal carcinoma by targeting ANLN and HSPA4L. Oncotarget 6: 35893-35907, 2015.

25. Strong MJ, Baddoo M, Nanbo A, Xu M, Puetter A and Lin Z: Comprehensive high-throughput RNA sequencing analysis reveals contamination of multiple nasopharyngeal carcinoma cell lines with HeLa cell genomes. J Virol 88: 10696-10704, 2014

26. Murphy JF, Lennon F, Steele C, Kelleher D, Fitzgerald D and Long AC: Engagement of CD44 modulates cyclooxygenase induction, VEGF generation, and proliferation in human vascular endothelial cells. FASEB J 19: 446-448, 2005.

27. Subramaniam V, Vincent IR, Gilakjan M and Jothy S: Suppression of human colon cancer tumors in nude mice by siRNA CD44 gene therapy. Exp Mol Pathol 83: 332-340, 2007.

28. Arpin M, Chirivino D, Naba A and Zwaenepoel I: Emerging role for ERM proteins in cell adhesion and migration. Cell Adhes Migr 5: 199-206, 2011.

29. Lin CH, Hung PH and Chen YJ: CD44 is associated with the aggressive phenotype of nasopharyngeal carcinoma through redox regulation. Int J Mol Sci 14: 13266-13281, 2013.

30. Takahashi-Yanaga $\mathrm{F}$ and Kahn M: Targeting Wnt signaling: Can we safely eradicate cancer stem cells? Clin Cancer Res 16: 3153-3162, 2010

31. Schmitt M, Metzger M, Gradl D, Davidson G and Orian-Rousseau V: CD44 functions in Wnt signaling by regulating LRP6 localization and activation. Cell Death Differ 22: 677-689, 2015.

32. Li T, Chen JX, Fu XP, Yang S, Zhang Z, Chen KhH and Li Y: microRNA expression profiling of nasopharyngeal carcinoma. Oncol Rep 25: 1353-1363, 2011.

33. Bao Y, Guo Y, Li Z, Fang W, Yang Y, Li X, Li Z, Xiong B, Chen Z, Wang $\mathrm{J}$, et al: MicroRNA profiling in Muc2 knockout mice of colitis-associated cancer model reveals epigenetic alterations during chronic colitis malignant transformation. PLoS One 9: e99132, 2014.

34. Machová Poláková K, Lopotová T, Klamová H, Burda P, Trněný M, Stopka T and Moravcová J: Expression patterns of microRNAs associated with CML phases and their disease related targets. Mol Cancer 10: 41, 2011.
35. Morris VA, Zhang A, Yang T, Stirewalt DL, Ramamurthy R, Meshinchi $S$ and Oehler VG: MicroRNA-150 expression induces myeloid differentiation of human acute leukemia cells and normal hematopoietic progenitors. PLoS One 8: e75815, 2013.

36. Zhao JJ, Lin J, Lwin T, Yang H, Guo J, Kong W, Dessureault S, Moscinski LC, Rezania D, Dalton WS, et al: microRNA expression profile and identification of miR-29 as a prognostic marker and pathogenetic factor by targeting CDK6 in mantle cell lymphoma. Blood 115: 2630-2639, 2010.

37. Wang M, Yang W, Li M and Li Y: Low expression of miR-150 in pediatric intestinal Burkitt lymphoma. Exp Mol Pathol 96: 261-266, 2014

38. Assumpção MB, Moreira FC, Hamoy IG, Magalhães L, Vidal A, Pereira A, Burbano R, Khayat A, Silva A, Santos S, et al: High-throughput miRNA sequencing reveals a field effect in gastric cancer and suggests an epigenetic network mechanism. Bioinform Biol Insights 9: 111-117, 2015.

39. Yokobori T, Suzuki S, Tanaka N, Inose T, Sohda M, Sano A, Sakai M, Nakajima M, Miyazaki T, Kato H, et al: miR-150 is associated with poor prognosis in esophageal squamous cell carcinoma via targeting the EMT inducer ZEB1. Cancer Sci 104: 48-54, 2013.

40. Watanabe A, Tagawa H, Yamashita J, Teshima K, Nara M, Iwamoto K, Kume M, Kameoka Y, Takahashi N, Nakagawa T, et al: The role of microRNA-150 as a tumor suppressor in malignant lymphoma. Leukemia 25: 1324-1334, 2011.

41. Chen S, Wang Z, Dai X, Pan J, Ge J, Han X, Wu Z, Zhou X and Zhao T: Re-expression of microRNA-150 induces EBV-positive Burkitt lymphoma differentiation by modulating c-Myb in vitro. Cancer Sci 104: 826-834, 2013.

42. Jia $Y$, Ling $M$, Zhang L, Jiang S, Sha $Y$ and Zhao R: Downregulation of miR-150 expression by DNA hypermethylation is associated with high 2-hydroxy-(4-methylthio)butanoic acid-induced hepatic cholesterol accumulation in nursery piglets. J Agric Food Chem 64: 7530-7539, 2016.

43. Endo K, Kondo S, Shackleford J, Horikawa T, Kitagawa N, Yoshizaki T, Furukawa M,Zen Y and Pagano JS: Phosphorylated ezrin is associated with EBV latent membrane protein 1 in nasopharyngeal carcinoma and induces cell migration. Oncogene 28: $1725-1735,2009$

44. Wang L, Lin GN, Jiang XL and Lu Y: Expression of ezrin correlates with poor prognosis of nasopharyngeal carcinoma. Tumour Biol 32: 707-712, 2011.

45. Tobo T, Hirahashi M, Yao T, Aishima $S$ and Oda Y: Ezrin expression and its phosphorylation in gastric carcinoma with lymphoid stroma and Epstein-Barr virus infection. Mol Clin Oncol 1: 220-224, 2013.

46. Teo JL and Kahn M: The Wnt signaling pathway in cellular proliferation and differentiation: A tale of two coactivators. Adv Drug Deliv Rev 62: 1149-1155, 2010. 